Research Article

\title{
Pore Structure and Fractal Characteristics of Shale under the Control of Bedding and Size: A Case Study of Shale from the Longmaxi Formation in China
}

\author{
Yao Cheng ${ }^{(D)},{ }^{1}$ Yifeng Xie ${ }^{D},{ }^{2}$ Yulin Ma ${ }^{D},{ }^{2}$ and Yanlin Zhao ${ }^{3}{ }^{3}$ \\ ${ }^{1}$ College of Innovation and Practice, Liaoning Technical University, Fuxin 123000, China \\ ${ }^{2}$ School of Mechanics and Engineering, Liaoning Technical University, Fuxin 123000, China \\ ${ }^{3}$ Hunan Provincial Key Laboratory of Safe Mining Techniques of Coal Mines, \\ Work Safety Key Laboratory on Prevention and Control of Gas and Roof Disasters for Southern Coal Mines, \\ Hunan University of Science and Technology, Xiangtan 411201, China \\ Correspondence should be addressed to Yifeng Xie; xieyifeng0820@163.com
}

Received 10 December 2020; Revised 2 April 2021; Accepted 19 April 2021; Published 27 April 2021

Academic Editor: Junhong Yuan

Copyright (c) 2021 Yao Cheng et al. This is an open access article distributed under the Creative Commons Attribution License, which permits unrestricted use, distribution, and reproduction in any medium, provided the original work is properly cited.

\begin{abstract}
In this study, the pore structure and fractal characteristics of shale samples with different bedding directions and sizes from the Longmaxi Formation of the Changning block in the Sichuan Basin were investigated by using CT imaging and low-temperature nitrogen adsorption experiments. The pore morphology, pore structure characteristics, relationships between the fractal dimensions and pore parameters, and effect of the size and bedding direction on pore morphology and various pore parameters were explored. In terms of pore structure characteristics, we found that the pores of shale samples were well developed and connected, forming a large number of pore clusters. The pores were mainly open pores and mesopores, which contributed the most to the specific surface area of the pores. Two fractal dimensions $D_{1}$ and $D_{2}$ were calculated from nitrogen adsorption data at relative pressures of $0-0.45$ and $0.45-1$, using the FHH method. These fractal dimensions characterized the pore surface and pore structure complexity, respectively. $D_{1}$ ranged from 2.773 to 2.923 , with a mean value of 2.821 , and $D_{2}$ varied from 2.853 to 2.899 , with a mean value of 2.874 . These variations indicated that there were irregular pore surfaces and sophisticated pore structures in the shale. The sample size and bedding direction had a significant impact on pore morphology and various pore parameters. Several pore characteristics of the vertical samples were superior to those of the horizontal samples. With an increase in size, the pore distribution became more uniform, the number of pore clusters increased, and the connectivity between pore clusters was enhanced. There was a good positive correlation between the fractal dimension $D_{2}$ and specific surface area and moderate positive correlation between $D_{2}$ and porosity and between $D_{2}$ and pore volume. However, the fractal dimension $D_{1}$ had a weak negative correlation with porosity and specific surface area and moderate negative correlation with pore volume. Moreover, both $D_{1}$ and $D_{2}$ tended to decrease with increasing average pore diameter.
\end{abstract}

\section{Introduction}

As a clean and efficient energy resource and chemical raw material, unconventional shale gas has attracted extensive attention from all over the world [1-4]. Over the last two decades, shale gas development has expanded from North America to other areas in the world, and research on shale gas exploration has accelerated. China's shale gas deserves attention and has extensive exploration significance due to its widespread development and distribution characteristics [1]. Because the energy situation is increasingly tense, research on shale gas has substantial utility for improving China's energy structure and reducing the reliance on conventional energy sources.

The Sichuan Basin is the most intensive and successful region for shale gas exploration and development in China at present. It is a large superimposed petroliferous basin with an approximate area of $19 \times 10^{4} \mathrm{~km}^{2}$ and is known for its rich 
natural gas [5]. There are six sets of organic-rich shale formations in the Sichuan Basin. Among them, the Lower Paleozoic Wufeng Formation-Longmaxi Formation is the most favorable shale gas segment with shale gas recoverable resources of about $5.30 \times 10^{12} \mathrm{~m}^{3}$. The Fuling, Weiyuan, Changning, and other shale gas fields with over 100 billion cubic meters were discovered in this segment. This section has entered the initial stage of industrial production and has held promise for the future production of $300 \times 10^{8}$ to $600 \times 10^{8} \mathrm{~m}^{3}$ [6]. Crucially, shale gas exploration and development in this region will provide valuable theoretical research and technical support for commercial shale gas development in China [1].

Shales are complex and heterogeneous porous media with low porosity and ultra-low permeability. Previous studies have demonstrated that shale has a wide-ranging pore size distribution, varied pore types, and multiple pore geometries [7-10]. Pore size determines the state of shale gas such that free gas is primarily stored in large pores or fractures, and adsorbed gas is mostly stored in small pores. Shale is a great mass of micro- and nanoscale pores and microcracks. According to the International Union of Pure and Applied Chemistry (IUPAC) classification, mesopores with diameters between 2 and $50 \mathrm{~nm}$ play a dominant role in shale $[11,12]$. Pore structure characteristics of shale reservoirs not only determine the gas storage and adsorption capacity of shale but also affect gas migration [13-16]. Therefore, the complex pore structure of shale is an important research field that is significantly important for gasbearing shale evaluation, exploration, and development.

Currently, the application of microvisualization analysis to obtain microphysical properties and capture internal behavior is becoming more and more extensive [17-26]. Field emission scanning electron microscopy (FE SEM) and nano-CT imaging have proven to be effective methods to characterize the morphology and structure characteristics of shale pores qualitatively [17-20]. Nitrogen adsorption, high-pressure mercury intrusion porosimetry, nuclear magnetic resonance, porosity, and permeability tests were employed to obtain the quantitative surface area, pore size distribution, pore volume, porosity, and permeability [23-26]. Among them, nitrogen $\left(\mathrm{N}_{2}\right)$ adsorption analysis has been proven to be an effective method to characterize pore structures in shales [27-29]. Adsorption data have also been utilized to investigate the fractal characteristics of pores in shale. The fractal theory is used to quantitatively analyze the complexity and regularity of the pore network by using fractal dimension $D$, which is considered to be a useful method to characterize the complex pore structure of porous materials and rock matrix [30-34].

Meanwhile, it is very important to study the influence of scale effect, defect, and failure state on rock properties. Lin et al. [35-37] have done a lot of instructive work in this point. The study in 36 investigated the scale effect of shear mechanical properties of nonpenetrating horizontal rock-like joints by PFC. The results indicate that the lower the persistence ration of the joint, the more obvious the negative scale effect of joint shear strength. Then, the numerical simulation of cyclic freeze-thawing of water-bearing joints was carried out through equivalent expansion coefficient and particle flow calculation methods. In [36], the distribution of frost heaving force in and around the joints was obtained. In [37], for the state of direct shear test, the Kachanov creep damage law was adopted to describe the time characteristics of the rock shear strength during the accelerated creep stage. The results show that the modified Burgers model can better reflect the mechanical properties of rock in three creep stages.

This study aimed to examine the pore structure of shales of the Longmaxi Formation in the Changning area of the Sichuan Basin in China using a combination of CT imaging and low-temperature $\mathrm{N}_{2}$ adsorption experiments. Shale samples of different bedding directions and sizes were investigated in this work. This aspect of shale has received little attention from researchers. Meanwhile, the fractal dimensions calculated at two different relative pressures $(\mathrm{P} / \mathrm{Po})$ were used to characterize the irregular degree of the pore surface and structure based on $\mathrm{N}_{2}$ adsorption data and the Frenkel-Halsey-Hill (FHH) model. The objectives of this study were as follows: (1) characterizing the pore morphology, pore size distribution, specific surface area, and volume; (2) investigating the effect of sample size and bedding direction on the pore morphology; (3) discussing the relationships between various pore parameters; (4) addressing the relationships between two fractal dimensions $D_{1}$ and $D_{2}$ and various pore structure parameters. The systematic results of this research will be useful for analyzing practical data errors caused by the size effect and have significance for the evaluation of the pore performance of shale originating from Longmaxi formation.

\section{Samples and Methods}

2.1. Samples. Shale samples used in the experiment were taken from Longmaxi Formation in the Changning area of China. Ten cores with the same height but different diameters were collected according to the horizontal and vertical bedding directions, respectively (Figure 1). Samples were numbered and size parameters are shown in Table 1.

\subsection{Methods}

2.2.1. X-Ray CT Imaging. The CT imaging test applies the $\mu \mathrm{CT} 225 \mathrm{KVFCB}$ high-precision $(\mu \mathrm{m}) \mathrm{CT}$ test analysis system (Figure 2). This system was jointly developed by the Taiyuan University of Technology, China Academy of Engineering Physics, and Institute of Applied Electronics to observe and analyze pore structure characteristics of shale samples. The image pixel matrix and display gray scale of the CT system reach orders 214 and 216, respectively, the limit power is $320 \mathrm{~W}$, the allowable voltage is $225 \mathrm{kV}$, the density resolution is less than or equal to $0.2 \%$, the maximum magnification is 400 , and the maximum pore and crack of $1 \mu \mathrm{m}$ can be resolved. In this research, CT images were dyed to cause pores to be displayed in red dots for more convenient observation.

\subsubsection{Low-Temperature $\mathrm{N}_{2}$ Adsorption Experiment.} Low-temperature nitrogen adsorption experiments were conducted using equipment TriStar II 3020 from 

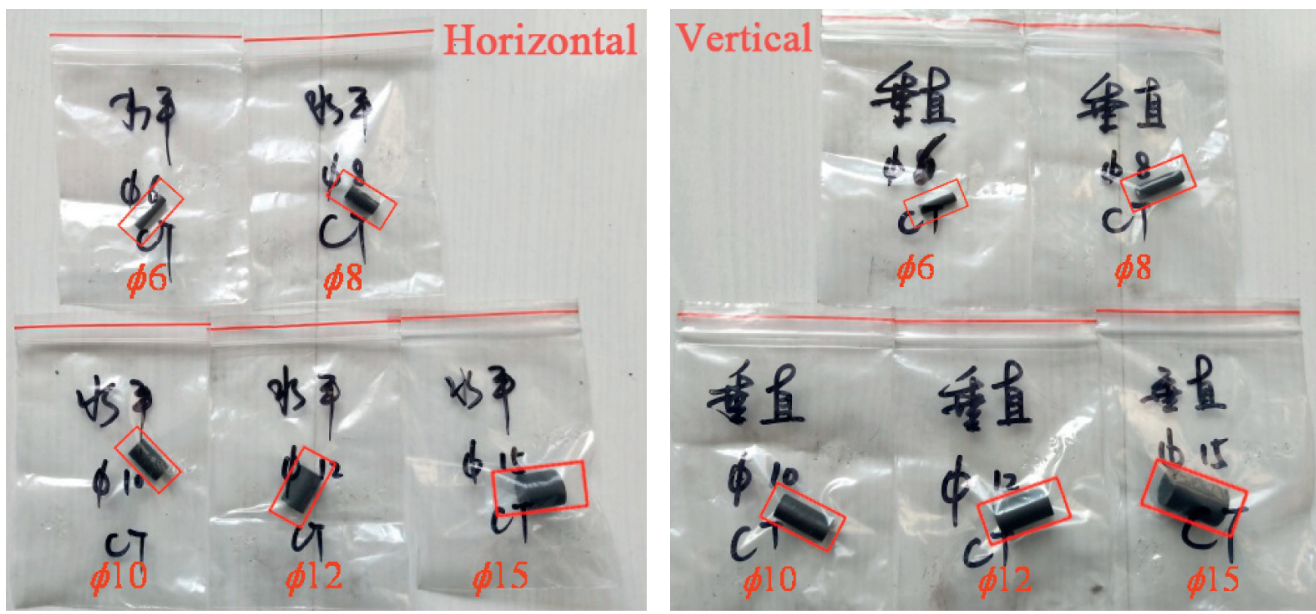

FIgURE 1: The shale sample images with different bedding directions.

TABLE 1: The size parameters of shale samples.

\begin{tabular}{lccc}
\hline Number & Bedding direction & Diameter $/ \mathrm{mm}$ & Height $/ \mathrm{mm}$ \\
\hline Shale 1\# & Horizontal & 6 & 15 \\
Shale 2\# & Vertical & 6 & 15 \\
Shale 3\# & Horizontal & 8 & 15 \\
Shale 4\# & Vertical & 8 & 15 \\
Shale 5\# & Horizontal & 10 & 15 \\
Shale 6\# & Vertical & 10 & 15 \\
Shale 7\# & Horizontal & 12 & 15 \\
Shale 8\# & Vertical & 12 & 15 \\
Shale 9\# & Horizontal & 15 & 15 \\
Shale 10\# & Vertical & 15 & 15 \\
\hline
\end{tabular}

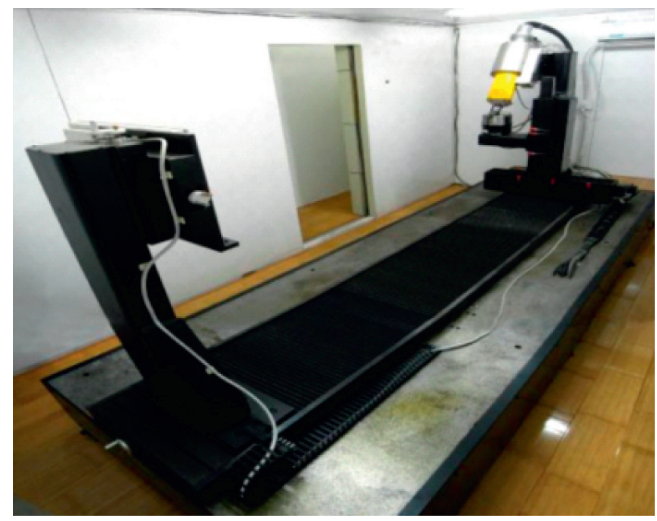

FIGURE 2: CT imaging system.

Micromeritics Instrument Corporation (Figure 3), with measured specific surface areas as small as $0.01 \mathrm{~m}^{2} / \mathrm{g}$. To eliminate the residual irreducible water and capillary water in the samples, all samples were pretreated by high-temperature vacuumization at $300^{\circ} \mathrm{C}$ for $3 \mathrm{~h}$ before the experiment. Then, nitrogen with purity greater than $99.999 \%$ was employed as adsorbate, and the nitrogen adsorption capacity under different relative pressures was measured at $-195.850^{\circ} \mathrm{C}$. Finally, we took the relative pressure as abscissa

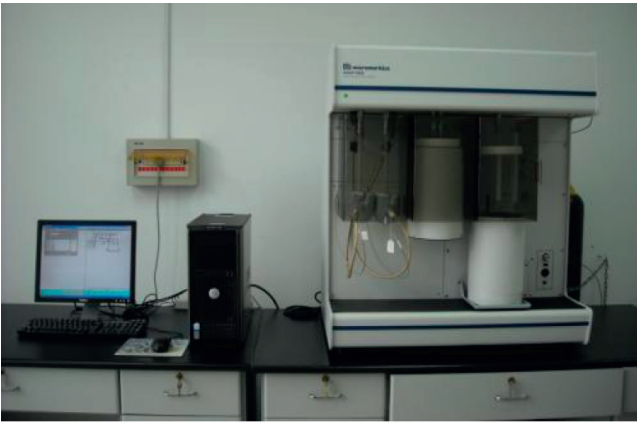

Figure 3: Automatic specific surface area and porosity analyzer.

and the adsorption amount per unit mass as ordinate to depict the adsorption/desorption isothermals.

2.2.3. Fractal Theory. Zhao et al. [38-41] studied rock joints, microfractures that affect surface roughness and heterogeneity. The fractal theory has been successfully applied to describe such irregularity of rock [42]. In this regard, the fractal dimension $D$ is utilized as an index of pore surface roughness or pore structure complexity of the solid [43]. The fractal FHH model based on gas adsorption data has been confirmed to be an effective method and has been broadly applied to determine fractal dimensions of several porous materials [44-46]. The FHH model can be simplified as follows:

$$
\ln V=K \ln \left(\ln \left(\frac{p_{0}}{p}\right)\right)+C
$$

where $p$ is equilibrium pressure $(\mathrm{MPa}), p_{0}$ is vapor pressure when gas adsorption reaches saturation, $V$ is the volume of adsorbed gas at the equilibrium pressure $p\left(\mathrm{~cm}^{3} / \mathrm{g}\right)$, and $C$ is a constant. The value of $K$ can be calculated by plotting $\ln V$ versus $\ln \left(\ln \left(p_{0} / p\right)\right)$. Then, the fractal dimension based on $\mathrm{N}_{2}$ adsorption data can be obtained from the slope $(K)$ : $D=3+K$ or $D=3+3 K$. The value of $D$ obtained from the latter has been demonstrated to be unrealistically small 
compared with that of the former [27]. Thus, $D=3+K$ was employed in this study with relative pressure that ranged from 0 to 1 .

\section{Results and Analysis}

3.1. Pore Morphology from CT Images. CT images of the 800th layer were used to observe the pore morphology of shale samples. Based on the 2D CT images (Figure 4), an $800 \times 800$ area was chosen, and then, a $100 \times 100$ area was selected above and below it. By stacking 100 layers downward (i.e., $800-900$ layers), a $100 \times 100 \times 1003 \mathrm{D}$ gray core was reconstructed, and then, pores were extracted through image binarization processing. The images were procured through $3 \mathrm{D}$ redrawing (Figure 5).

The brighter the 2D CT images were, the greater the density of shale composition was. The shale composition was composed of mineral components, such as pyrite. By contrast, the smaller the density was, the darker the images were, and this indicated organic matter. Nonisolated organic matters often appeared with minerals in the form of adsorbing, wrapping, or filling, with a gray-white or grayblack in the images. As displayed in the 2D CT images in Figure 4, where the red highlighted areas were pores, organic matters showed obvious porosity. The distribution of minerals, organic matters, and pores all demonstrated certain microscopic heterogeneity, and their size, shape, and number were quite different in different areas. Pores developed abundantly in the shale, forming many connected pore clusters. This was because of the abundant and randomly distributed organic pores. These organic pores were connected with a small number of inorganic pores like intergranular pores and intragranular pores in shale, forming microscopic seepage channels for gas reserves and migration in shale reservoirs.

Based on the $2 \mathrm{D}$ images and $3 \mathrm{D}$ reconstructed images, we found that the shale was a heterogeneous porous medium with rich pore development, and the overall pore distribution of each sample appeared similar. The 2D CT images indicated that pores approximately exhibited a circular distribution. There were more pores near the center of the circle, while the number of pores at the distal part gradually decreased. The content of high-density minerals in the center was less, and organic matters predominantly connected, showing irregular shapes. The $3 \mathrm{D}$ reconstruction images demonstrated that the overall shape of pore clusters was chiefly spherical or polygonal. Also, micron-scale pores were connected with other pores to form flow channels concentrated principally in the central area, while a large number of the nanoscale pores could only be distributed as isolated reservoir spaces in the periphery due to poor connectivity. The porosity and threshold of samples are shown in Table 2.

\subsection{Analysis of $\mathrm{N}_{2}$ Adsorption}

3.2.1. $\mathrm{N}_{2}$ Adsorption/Desorption Curves. Four shale samples (shale $3 \#$, shale $4 \#$, shale $5 \#$, and shale $6 \#$ ) were selected, and their low-temperature nitrogen adsorption data were collected for analysis. Figure 6 shows nitrogen adsorption/ desorption isotherms of shale samples with diameters of $8 \mathrm{~mm}$ and $10 \mathrm{~mm}$ in the horizontal/vertical bedding direction. It can be observed that the adsorption isotherms of each sample were slightly different in morphology but all showed a reverse " $S$ " shape.

Based on the IUPAC classification, the adsorption isotherms of four shale samples belonged to Type IV. This indicated that shale samples possessed a continuous and complete pore system that developed from micropore to macropore. When the relative pressure was smaller than 0.4 , the adsorption branch and the desorption branch were almost coincident, and the isotherm rose gently and was slightly convex upward. $\mathrm{N}_{2}$ could be adsorbed on the surface of pores in the form of monolayer coverage at this stage. In the stage of relative pressure between 0.4 and 0.8 , the desorption branch displayed an obvious inflection point, and the adsorption branch showed a downward concave shape, which resulted in a hysteresis loop. This process belonged to the stage of multilayer coverage. When the relative pressure ranged from 0.8 to 1.0 , the adsorption branch rose sharply but did not approach saturated adsorption, even though the relative pressure approached the saturated vapor pressure. At this stage, the capillary condensation occurred within the mesopores [47]. This phenomenon suggested that these samples were principally dominated by micropores (smaller than $2 \mathrm{~nm}$ ) and mesopores (between 2 and $50 \mathrm{~nm}$ ), with few macropores (larger than $50 \mathrm{~nm}$ ).

The shape of the hysteresis loop could reflect the shape of the pores of the shale. According to the IUPAC classification, the shape of the hysteresis loop of the four samples indicated that the shape was somewhere between type $\mathrm{H} 2$ and H3. Type $\mathrm{H} 2$ hysteresis took place in pores with a narrow pore throat and wide bodies (defined as ink-bottleshaped pores) and in a small number of parallel-plate pores or cylindrical pores. Type $\mathrm{H} 3$ hysteresis indicated slit-shaped or wedge-shaped pores, which suggested that the shape of the pores in the samples was a combination of ink-bottle-like and slit- or plate-like. The former was primarily related to organic matter pores and intergranular pores, while the latter was related to intragranular pores or microcracks between clay mineral layers. This suggested that the micropores were developed, and simultaneously, some intragranular pores and microcracks between clay mineral layers developed, with great pore connectivity.

3.2.2. Pore Size Distribution, Specific Surface Area, and Pore Volume by $\mathrm{N}_{2}$ Adsorption. The specific surface area was calculated by the Brunner-Emmet-Teller (BET) adsorption isotherm formula [48]. The BET linear diagram was created for the range of relative pressure between 0.05 and 0.35 to obtain the saturated adsorption amount of monolayer. Then, the BET specific surface area of the sample could be obtained. Pore size distribution was calculated by the $\mathrm{BJH}$ method [49] based on the desorption branch of the isotherm. Moreover, the pore volume and average pore diameter were calculated from the nitrogen adsorption quantity when the relative pressure was about 0.993 . 

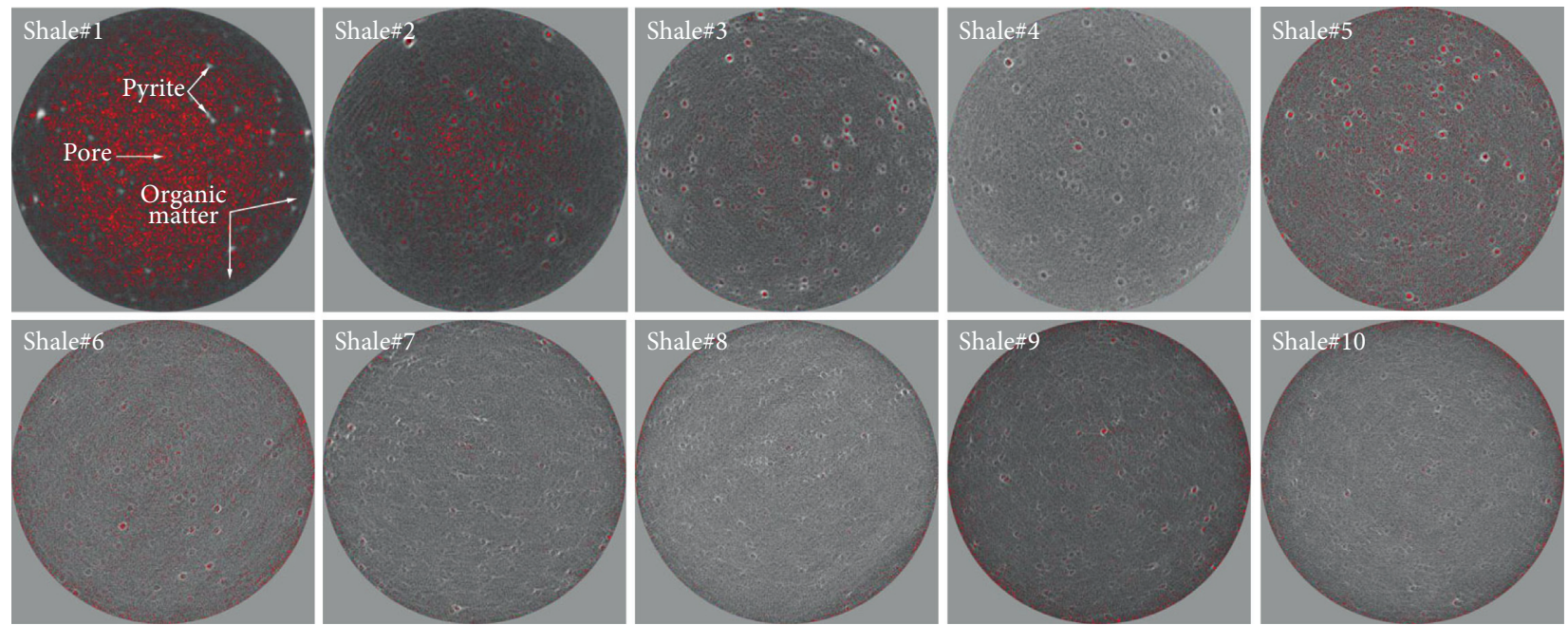

Figure 4: 2D CT scanning images.
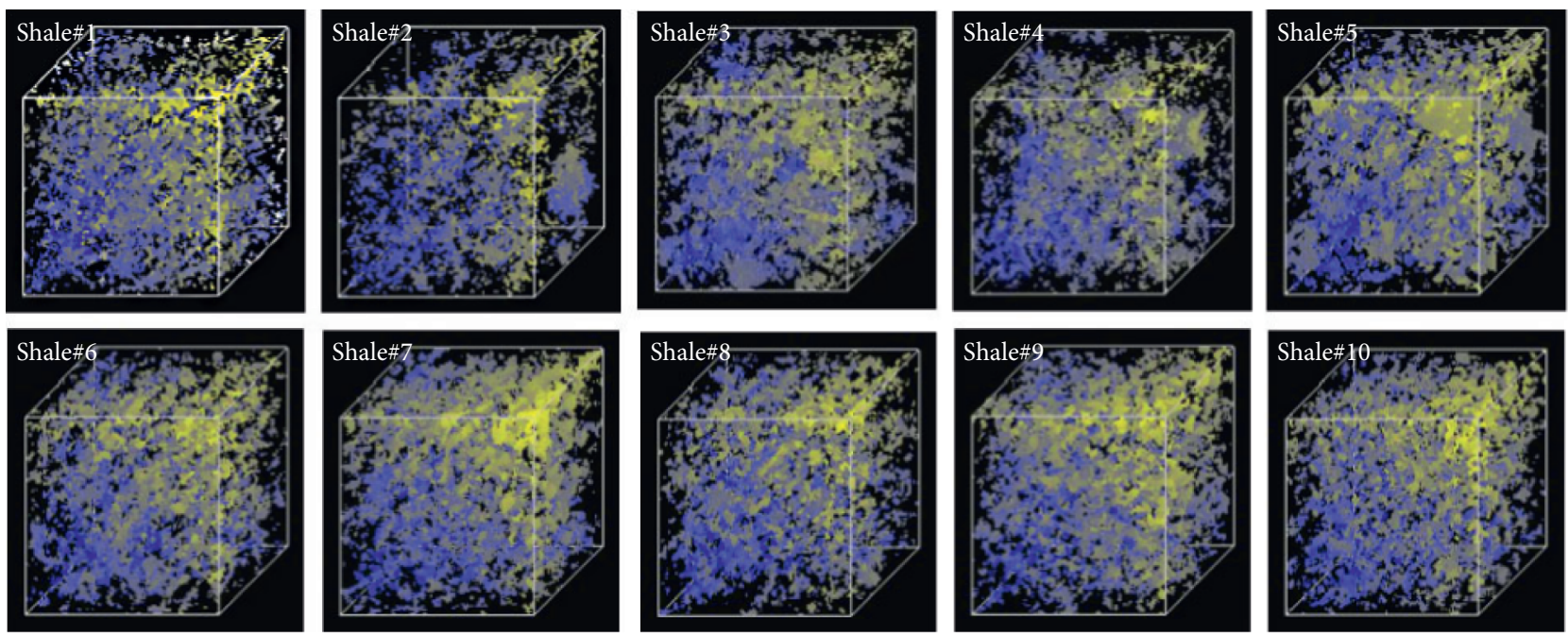

FIGURE 5: 3D reconstructed images.

TABLE 2: Porosity and threshold of shale samples.

\begin{tabular}{lcccc}
\hline \multirow{2}{*}{ Number } & \multicolumn{2}{c}{ Plane } & \multicolumn{2}{c}{ Stereoscopic } \\
& Porosity & Threshold & Porosity (\%) & Threshold \\
\hline Shale 1\# & 3.5614 & 0.01572 & 3.5537 & 0.01519 \\
Shale 2\# & 2.5514 & 0.01825 & 2.5415 & 0.01914 \\
Shale 3\# & 4.6078 & 0.01973 & 4.6032 & 0.02058 \\
Shale 4\# & 3.9339 & 0.02107 & 3.9324 & 0.02318 \\
Shale 5\# & 5.1311 & 0.01919 & 5.1304 & 0.01938 \\
Shale 6\# & 4.2603 & 0.01849 & 4.2636 & 0.01858 \\
Shale 7\# & 5.1317 & 0.02498 & 5.1298 & 0.02430 \\
Shale 8\# & 4.2656 & 0.02471 & 4.2647 & 0.02486 \\
Shale 9\# & 5.1344 & 0.02345 & 5.1387 & 0.02283 \\
Shale 10\# & 4.2675 & 0.02312 & 4.2616 & 0.02258 \\
\hline
\end{tabular}

The pore structure parameters (i.e., specific surface area, pore volume, and average pore diameter) were obtained from $\mathrm{N}_{2}$ adsorption. They are shown in Table 3. The specific surface area was between $11.54 \mathrm{~m}^{2} / \mathrm{g}$ and $24.69 \mathrm{~m}^{2} / \mathrm{g}$, with a mean value of $18.03 \mathrm{~m}^{2} / \mathrm{g}$. Pore volume ranged from $0.00961 \mathrm{~mm}^{3} / \mathrm{g}$ to $0.01936 \mathrm{~mm}^{3} / \mathrm{g}$, with an average value of $0.01841 \mathrm{~mm}^{3} / \mathrm{g}$. The average pore diameter generally was in the range of $3.14-3.52 \mathrm{~nm}$, with an average value of $3.38 \mathrm{~nm}$, which was considered mesopore-sized.

Figure 7 exhibits pore size distribution curves achieved by $\mathrm{BJH}$ theory, which could indicate the contribution of pore diameter to pore volume. It can be observed that the pore size distribution of shale samples was complex, and there were many different peaks in Figure 7 (a), which mainly concentrated at $502-15 \mathrm{~nm}$. For shale $6 \#$, the pore diameter peak chiefly concentrated at about $10 \mathrm{~nm}$, which indicated that the pore number was the largest in this range. For shale 5 \#, the pore size was largely distributed at about $5 \mathrm{~nm}$, while, for shale 3 \# and shale 4 \#, the pore size was mostly distributed at about 5-20 nm. These observations suggested that the pore size distribution of the shale samples was mainly mesoporous, which was the main place for gas adsorption and storage. Meantime, shale samples possessed certain macropores, 

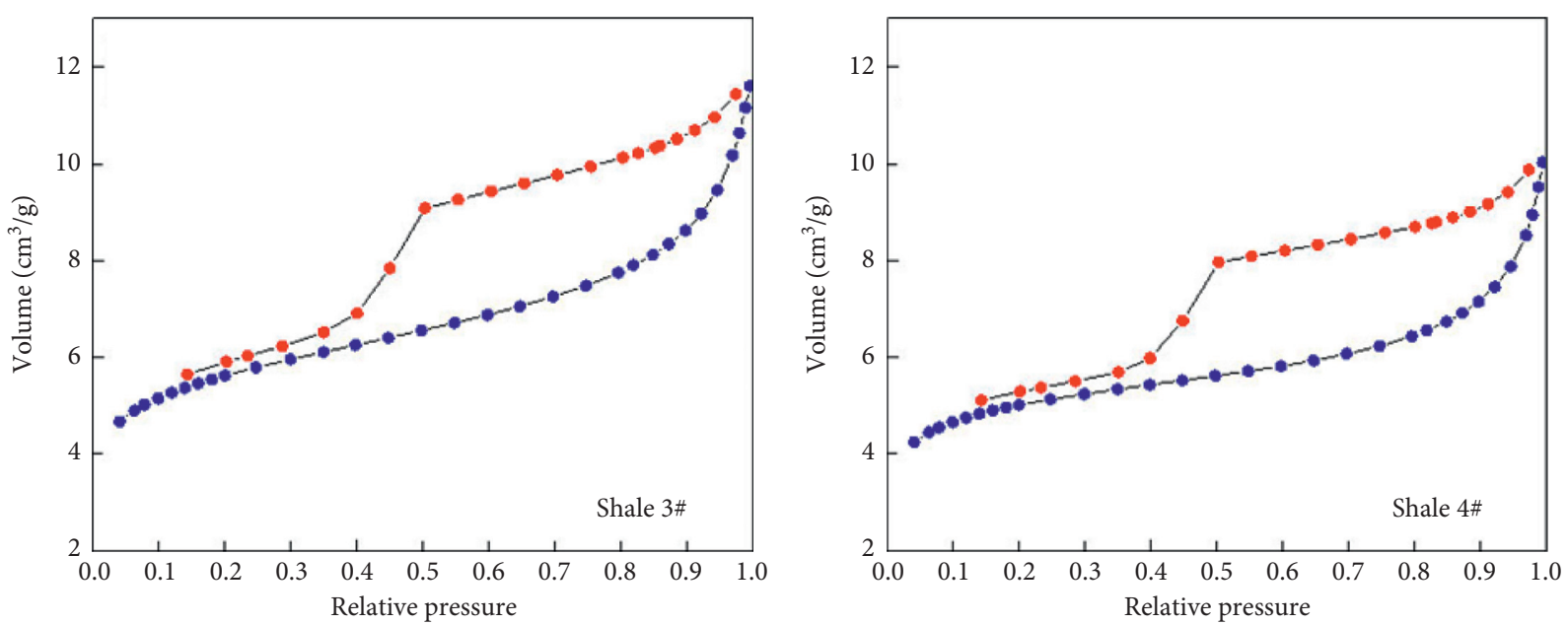

$\rightarrow$ 8-vertical-adsorption

-๑ 8-vertical-desorption
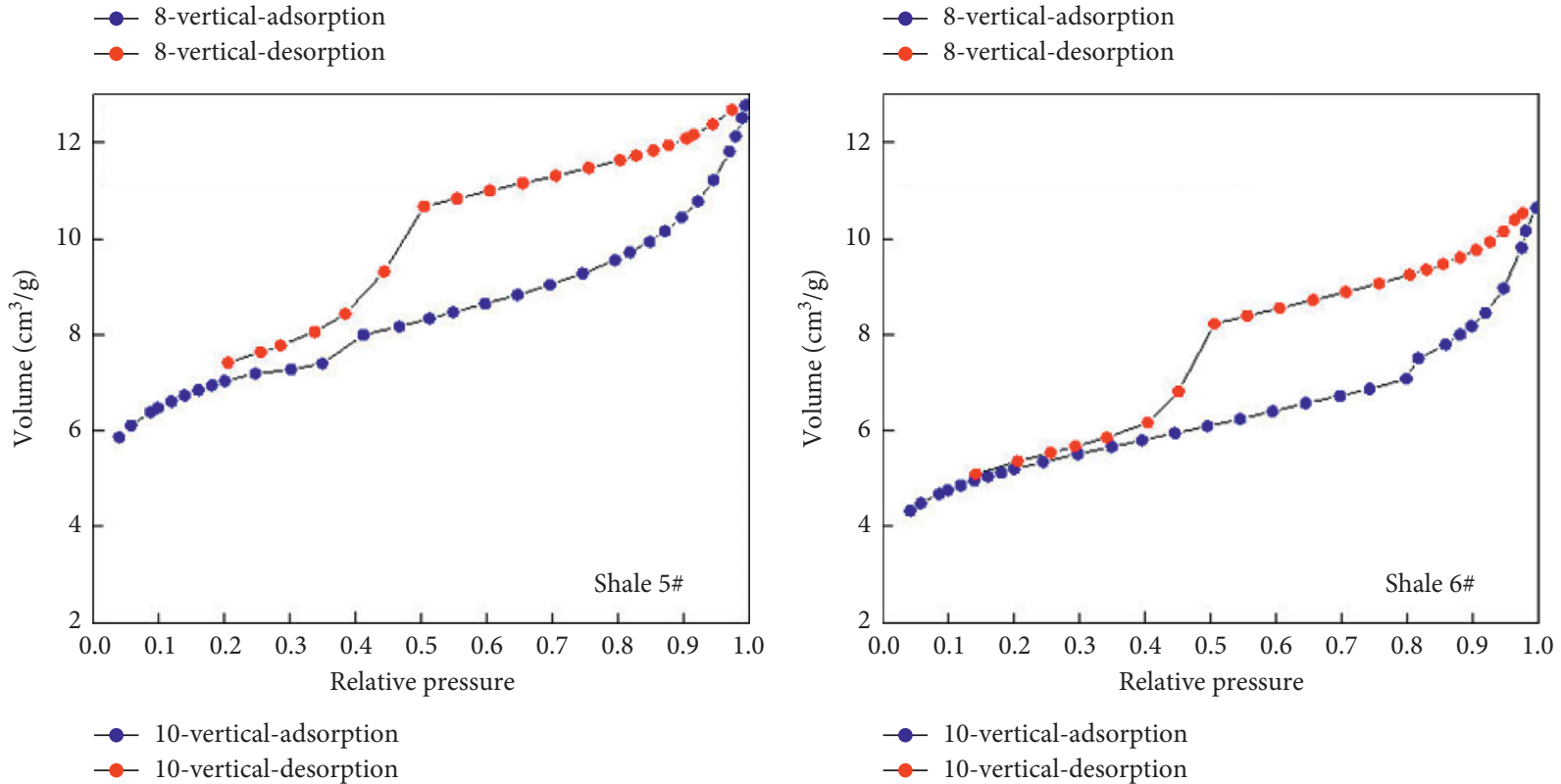

Figure 6: The isotherms of shale $3 \#$, shale $4 \#$, shale $5 \#$, and shale $6 \#$.

TABLE 3: Pore structure parameters of shale samples.

\begin{tabular}{lccc}
\hline Sample & BET specific surface area $/ \mathrm{m}^{2} \cdot \mathrm{g}^{-1}$ & BJH pore volume $/ \mathrm{mm}^{3} \cdot \mathrm{g}^{-1}$ & Average pore diameter/nm \\
\hline Shale 2\# & 11.5426 & 0.0096 & 3.3292 \\
Shale 3\# & 19.7704 & 0.0173 & 3.5079 \\
Shale 4\# & 17.3255 & 0.0148 & 3.4249 \\
Shale 5\# & 24.6946 & 0.0194 & 3.1357 \\
Shale 6\# & 18.2767 & 0.01601 & 3.5233 \\
\hline
\end{tabular}

which resulted in a "tailing phenomenon" in the pore size distribution curve. According to Figure 7(b), the increment of pore volume reduced with the increase of pore size, and the increase of total pore volume gradually tended to be gentle. The pore volume of mesopore accounted for the majority of the total volume (i.e., micropores and mesopores with a pore size smaller than $50 \mathrm{~nm}$ in shale provided the main specific surface area and pore volume), and the pores were the main places for gas adsorption and storage.
3.2.3. Fractal Dimensions from $\mathrm{N}_{2}$ Adsorption Data. According to the fractal FHH model, the $\ln \left(\ln \left(p_{0} / p\right)\right)$ versus $\ln (V)$ plots and calculated fractal dimension results of samples shale $6 \#$, shale $5 \#$, shale $4 \#$, shale $3 \#$, and shale $2 \#$ from $\mathrm{N}_{2}$ adsorption data are shown in Figure 8 and Table 4. The plots have a good linear relationship, and the correlation coefficients are mostly greater than 0.9 , suggesting that the pores in shale samples showed excellent fractal characteristics. Based on the fractal theory, the fractal dimension that 


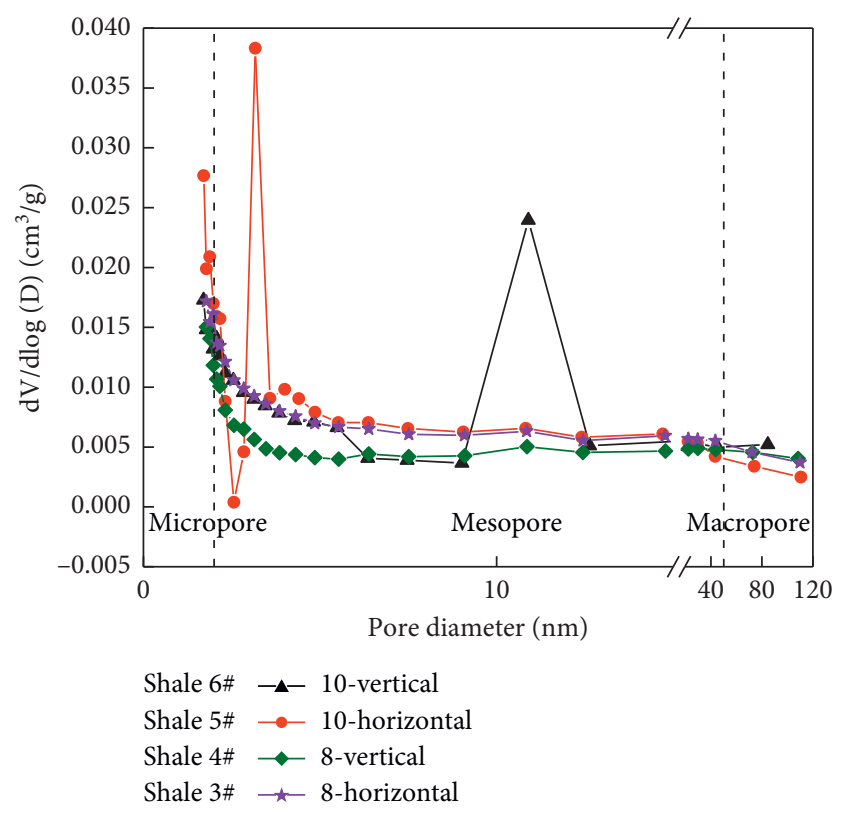

(a)

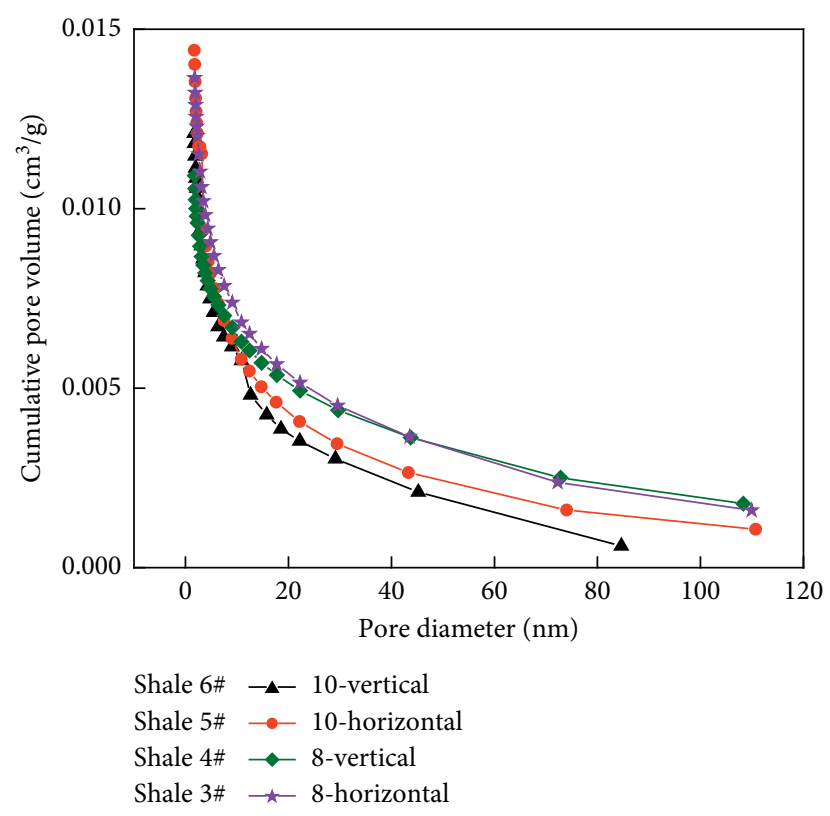

(b)

Figure 7: Pore size distribution of shale samples: (a) the relationship between pore size and rate of change of pore volume with the pore size; (b) the relationship between pore volume increment and pore size.

approaches three means that the surface is complex, and the roughness is increased.

Two distinct straight line segments at a relative pressure $\left(P / P_{0}\right)$ of $0-0.45$ and $0.45-1$ are shown in plots, representing two significant phases of the $\mathrm{N}_{2}$ adsorption process as mentioned before. The pore spaces in shale had different fractal characteristics in these two regions, $D_{1}$ and $D_{2}$, which were used to characterize the pore surface and pore structure complexity, respectively. From Table 4, values of fractal dimension $D_{1}$ ranged from 2.773 to 2.923 with a mean value of 2.821, and values of fractal dimension $D_{2}$ ranged from 2.853 to 2.899 with a mean value of 2.874 , which demonstrated that there were irregular pore surfaces and sophisticated pore structures in shales. The value of fractal dimension $D_{1}$ was generally smaller than the fractal dimension $D_{2}$. This indicated that the larger pores had a rougher pore surface and more complex pore structure compared with the smaller pores.

\section{Discussion}

4.1. The Effect of Sample Size and Bedding Direction on Pore Morphology. Shale samples with different bedding directions showed obviously different pore structure characteristics. Figure 3 indicates that shale 2 \# had a smaller density of mineral composition and a significantly less number of pores compared with shale $1 \#$. According to the $3 \mathrm{D}$ images, the pore clusters of sample shale $2 \#$ were rarely connected, which implied that they existed as independent reservoir spaces. The number of pore clusters wrapped by brittle minerals and clay minerals of sample shale $4 \#$ was more than that of sample shale $3 \#$ in the $3 \mathrm{D}$ images, and most of the pore clusters were connected. At the same time, shale $4 \#$ had an equivalent number of isolated pore clusters compared with that of shale $3 \#$, which had obviously a smaller scale. Based on the $2 \mathrm{D}$ images of shale $6 \#$, the distribution range of pores somewhat decreased compared with shale 5\#, and pore clusters were wrapped by brittle minerals, and clay minerals were fewer and smaller. From the 3D images, isolated pore clusters increased and enlarged. The pores morphology from the $2 \mathrm{D}$ images of shale $8 \#$ was similar to that of shale $7 \#$, but the overall amounts of pores decreased. The 3D images demonstrated that the pore connectivity of samples was better in the central part and worse peripherally, and the volume of isolated pore clusters was larger peripherally. The distribution of pores of shale 10\# was similar to that of shale $9 \#$ in the $2 \mathrm{D}$ images, but the number of pores obviously diminished compared with that of shale 9\#. The 3D images suggested that the connectivity between pore clusters was better in the central, and the number of surrounding isolated pore clusters was larger and its volume was smaller. In summary, the degree of connectivity between pore clusters and the size and number of isolated pore clusters of vertical samples were better than those of horizontal samples.

For samples with the same bedding direction, pore morphology was related to the size. From the 3D images of each sample in the same bedding direction, we found that with the increase of the diameter of samples, pore distribution became more uniform, the number of pore clusters increased, and the number of pores in pore clusters increased. Moreover, the connectivity between pore clusters was enhanced, and the number and size of isolated pore clusters decreased peripherally. Note that the volume of pore clusters had no obvious relationship with the size. Parameters. Based on the porosity data (Table 2), the 

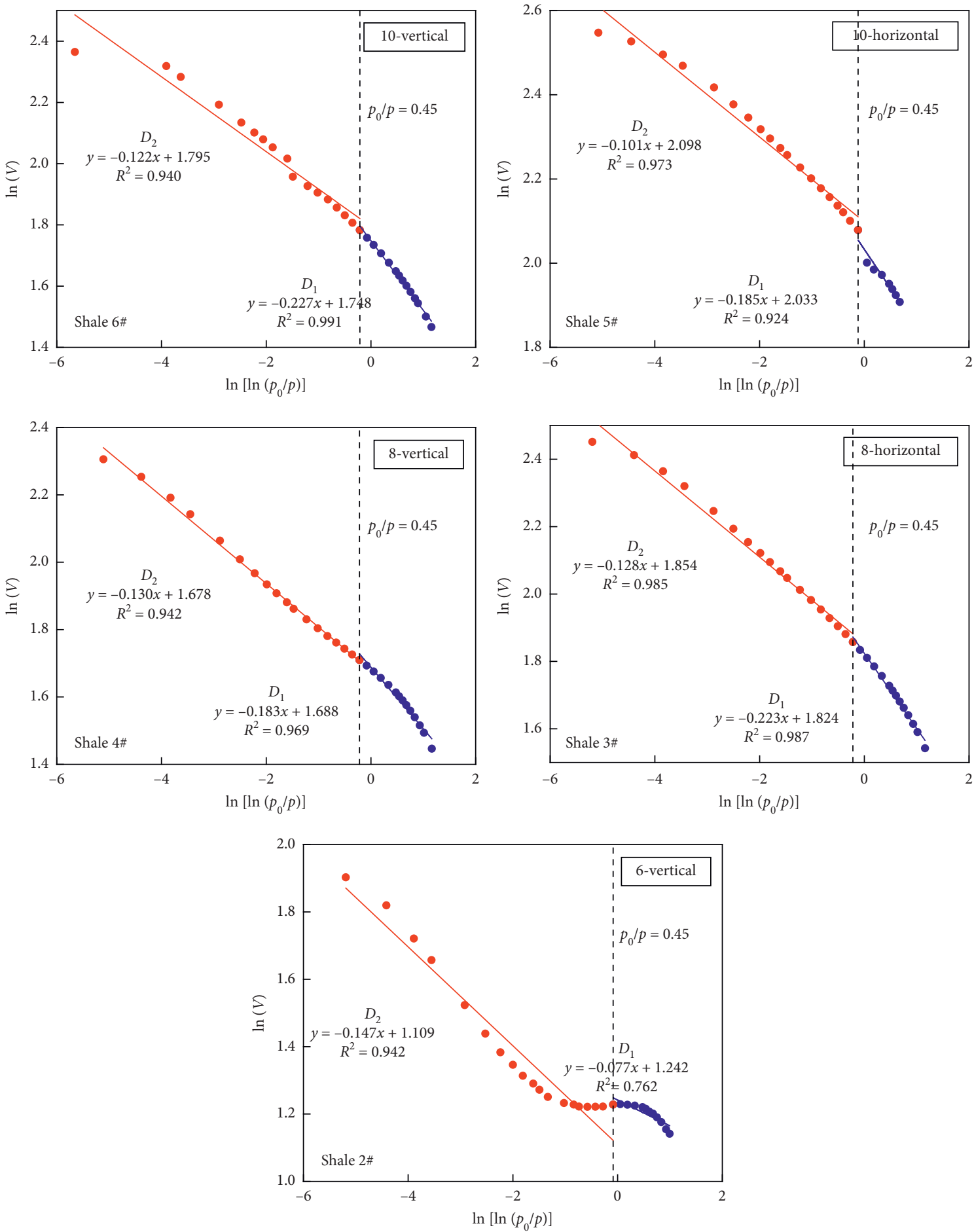

FIgURE 8: Double logarithm curves of adsorption volume by low-temperature nitrogen pressure.

calculated average porosity of samples was estimated to be $3.56 \%, 2.55 \%, 4.61 \%, 3.93 \%, 5.13 \%, 4.26 \%, 5.13 \%, 4.27 \%$, $5.13 \%$, and $4.26 \%$, respectively. Compared with the porosity of horizontal shale samples, the porosity of vertical shale samples lessened by about 17\%, averagely. Figure 9 shows the relationship between sample size and porosity of the samples with vertical/horizontal bedding, respectively. As indicated, with the increase of the size, the porosity of the sample increased slowly and tended to be stable in the range of $10 \mathrm{~mm}$ to $15 \mathrm{~mm}$. We found that when the size of the samples was quite small, the porosity had a positive correlation with the size, while the porosity had no relationship with the size when the size reached a certain value. We also found that the porosity curve of vertical bedding samples was always above the porosity curve of horizontal bedding samples. 
TABLe 4: Fractal dimensions derived from the FHH model.

\begin{tabular}{lcccrrr}
\hline \multirow{2}{*}{ Shale samples } & \multicolumn{2}{c}{$P / P_{0}=0-0.45$} & \multicolumn{3}{c}{$P / P_{0}=0.45-1$} \\
& Fitting equation & $D_{1}$ & $R^{2}$ & Fitting equation & $D_{2}$ \\
\hline Shale 6 \# & $y=-0.227 x+1.748$ & 2.773 & 0.991 & $y=-0.122 x+1.795$ & 2.878 \\
Shale 5 \# & $y=-0.185 x+2.033$ & 2.815 & 0.924 & $y=-0.101 x+2.098$ & 2.899 \\
Shale 4 & $y=-0.183 x+1.688$ & 2.817 & 0.969 & $y=-0.130 x+1.678$ & 2.870 \\
Shale 3 $\#$ & $y=-0.223 x+1.824$ & 2.777 & 0.987 & $y=-0.128 x+1.854$ & 0.940 \\
Shale 2 \# & $y=-0.077 x+1.242$ & 2.923 & 0.762 & $y=-0.147 x+1.109$ & 0.942 \\
\hline
\end{tabular}

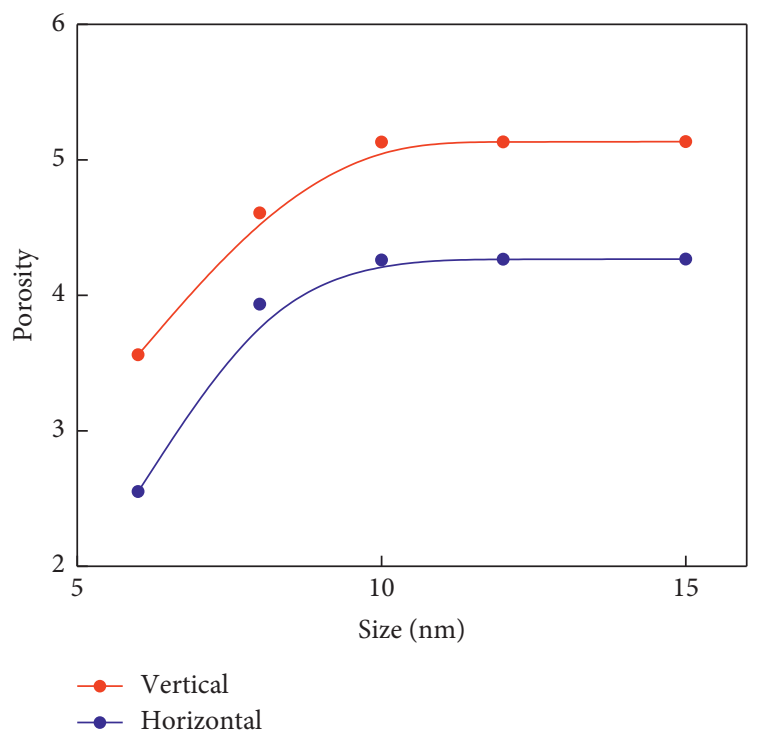

FIGURE 9: The relationship between shale sample size and porosity.

From the ordinate data of Figure 6, the bedding direction and size had an impact on the adsorption characteristics of the shale samples. The gas content in the adsorption process of the horizontal bedding samples was greater than that of the vertical bedding samples. With the increase of sample size, adsorption amounts of the sample also increased. From pore structure parameters of shale samples in Table 3, the specific surface area and pore volume of horizontal bedding samples were larger than those of the vertical bedding samples. The specific surface area and pore volume increased with the size of the samples. That is, the size and bedding direction of the samples had a direct influence on the pore specific surface area and pore volume. Besides, the average pore diameter and pore size distribution of shale samples were not clearly related to the size and bedding direction of samples. The larger the specific surface area, the stronger the adsorption capacity. Thus, although the specific surface area of shale pores could not be directly characterized by shale size due to the complexity of pores, the larger size and volume of shale corresponded to the larger total specific surface area. Therefore, the size of shale samples correlated with adsorption capacity to a certain extent.

4.3. Characteristics of the Pore Structure Parameters. The relationships among various pore structure parameters of the shale samples of the Longmaxi Formation are illustrated in Figure 10. The specific surface area increased with increasing pore volume, with a correlation coefficient $R^{2}=0.939$, which was consistent with the previous studies $[27,50,51]$. Weak negative correlations between average pore size and BET specific surface area and BJH pore volume are observed in Figures 10(b) and 10(c), which agreed with the previous studies [52]. This indicated that the pore volume and specific surface area increased with decreasing average pore size, and the effect on the specific area was larger. From the analysis of pore size distribution, micropores and mesopores with pore size $<50 \mathrm{~nm}$ in shales provided the main specific surface area and pore volume. Moreover, shales with smaller average pore diameter had more micropores and mesopores, which could lead to a larger specific surface area and pore volume.

4.4. The Relationships between Pore Parameters and Fractal Dimensions. Figure 11 reveals the relationships between fractal dimension $\left(D_{1}\right.$ and $\left.D_{2}\right)$ and pore structure parameters (porosity, specific surface area, pore volume, and average pore diameter) in Longmaxi Formation shales. The surface fractal dimension $D_{1}$ had a negative correlation with porosity, and the pore structure complexity fractal dimension $\mathrm{D}_{2}$ showed a positive correlation with porosity (Figure 11(a)). With the increase of total porosity, the ratio of large pores increased, and the ratio of small pores diminished. The increased pore size reduced the specific surface area of shale pores, which in turn reduced surface fractal dimensions. Small pores contributed to shale porosity to a certain extent. Hence, a moderate negative relationship between porosity and surface fractal dimension was depicted in the plot. Pore distribution became more complicated with increasing shale porosity, which led to an increase in the pore structure complexity fractal dimension.

There was a good positive correlation between the fractal dimension $D_{2}$ and specific surface area $\left(R^{2}=0.903\right.$ in Figure 11(b)) and moderate positive correlation between the fractal dimension $D_{2}$ and pore volume $\left(R^{2}=0.773\right.$ in Figure $11(\mathrm{c})$ ). However, the fractal dimension $D_{1}$ had a weak negative relationship with specific surface area $\left(R^{2}=0.294\right.$ in Figure 11(b)) and moderate negative correlation with pore volume $\left(R^{2}=0.568\right.$ in Figure $\left.11(\mathrm{c})\right)$. The good or moderate positive relationships demonstrated that shales with a greater surface area and pore volume had greater fractal dimensions and more complicated pore structure, which was consistent with the previous studies [27, 50-52]. Weak or moderate negative relationships did not agree with the results of previous studies. Generally, a reduction in the specific surface area of shale pores caused a reduction in 


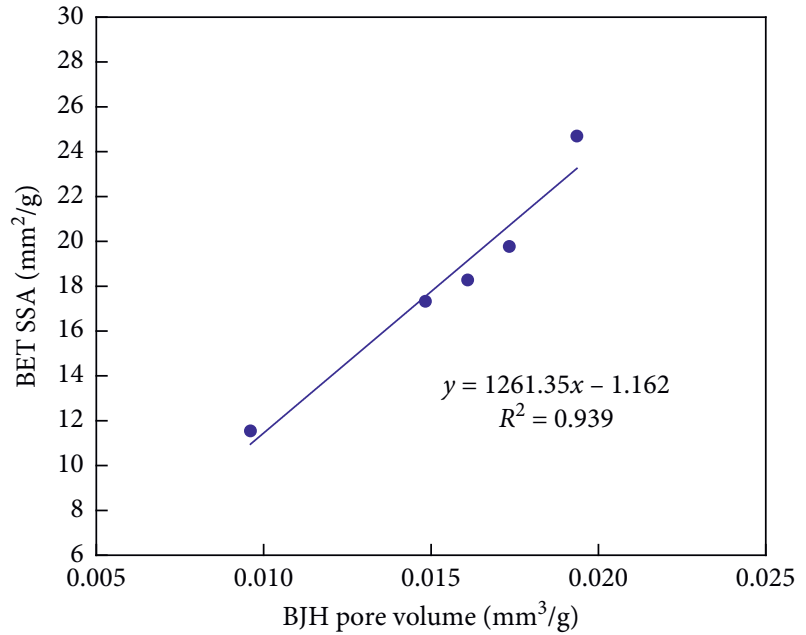

(a)

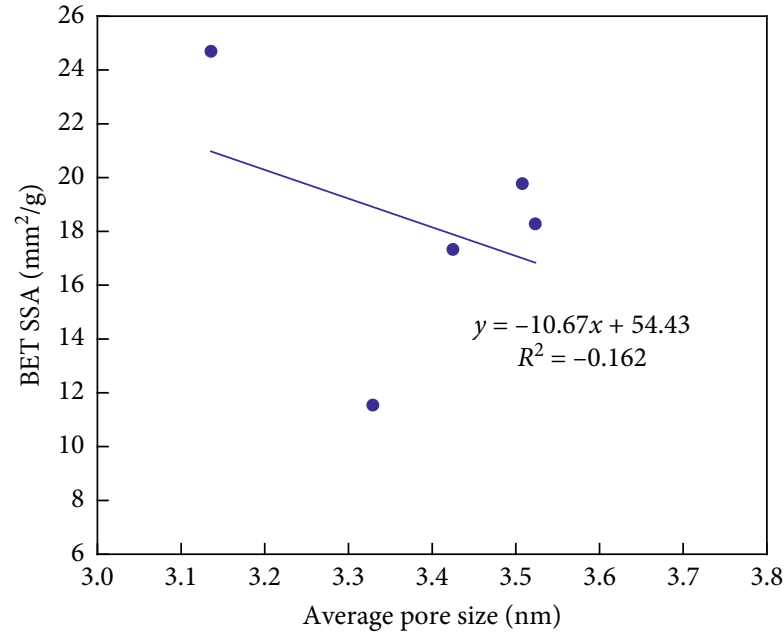

(b)

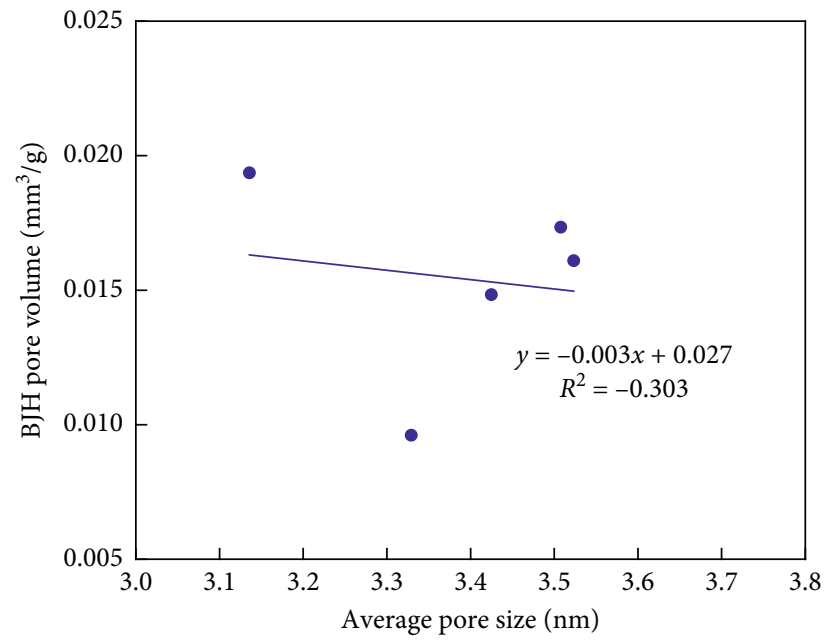

(c)

FIGURE 10: Relationships between (a) BET specific surface area and BJH pore volume, (b) BET specific surface area and average pore size, and (c) $\mathrm{BJH}$ pore volume and average pore size.

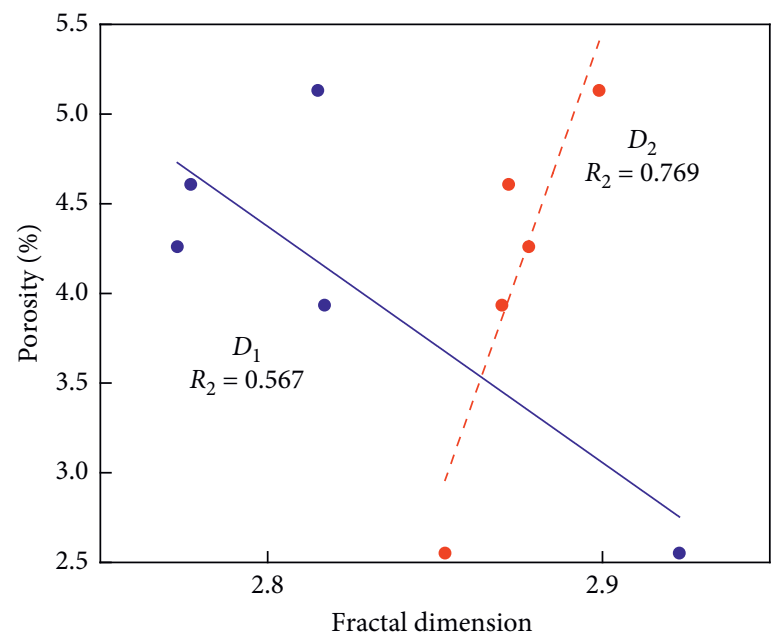

(a)

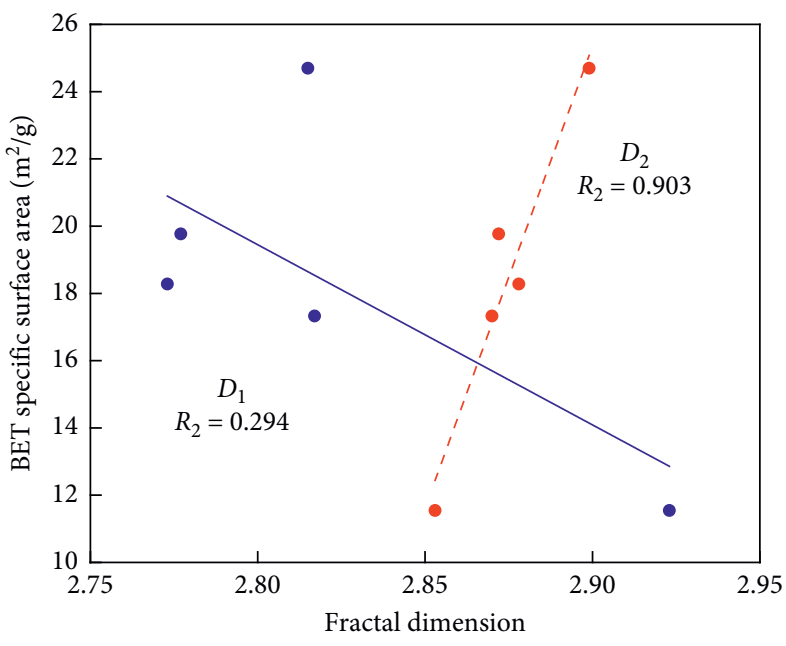

(b)

Figure 11: Continued. 


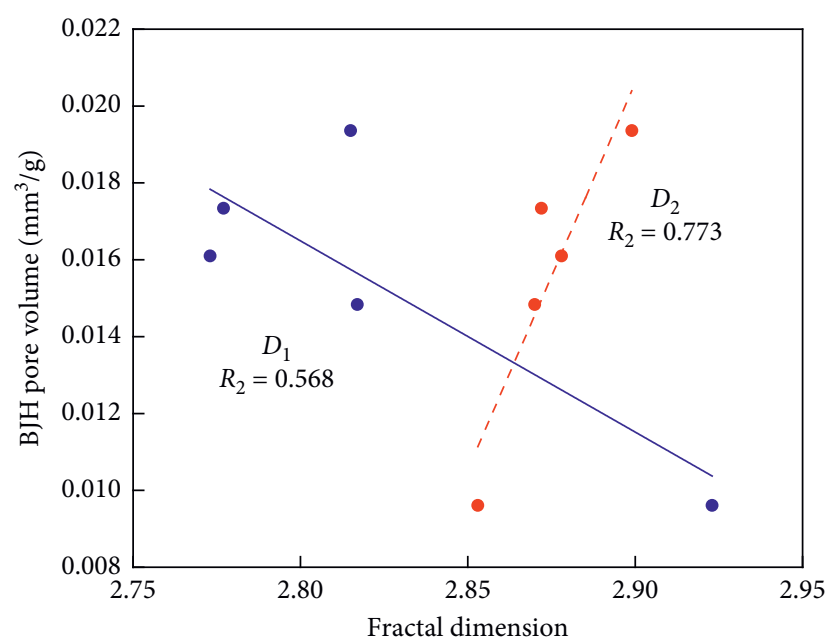

(c)

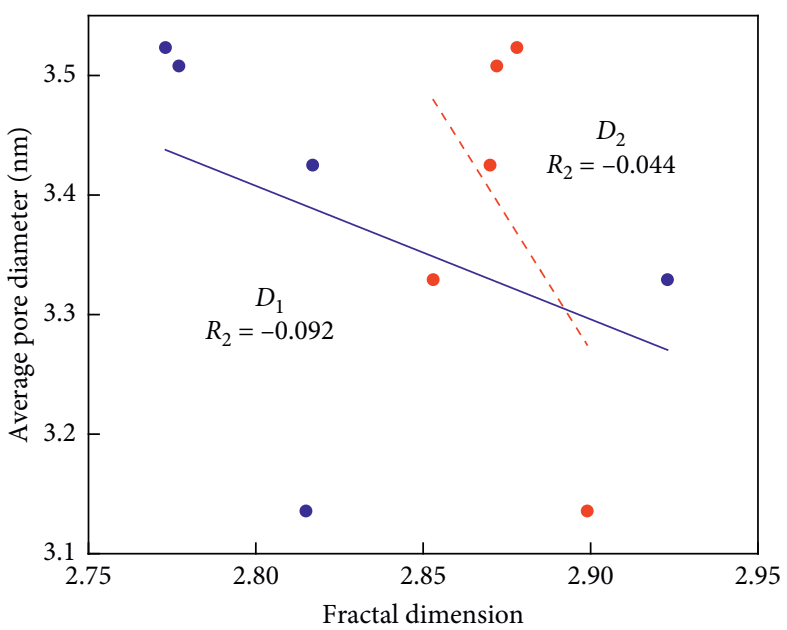

(d)

FIgURE 11: The relationships between fractal dimension $\left(D_{1}\right.$ and $\left.D_{2}\right)$ and (a) porosity, (b) BET specific surface area, (c) BJH pore volume, and (d) average pore size.

surface fractal dimensions. Moreover, an increase in the pore volume led to a larger fractal dimension and complicated pore distribution. The reason for these observations might come from insufficient sample data for drawing. This caused the fitting results to be affected by individual samples with a small specific surface area or pore volume and with a large fractal dimension. The relationship between fractal dimension and average pore diameter is shown in Figure 11(d), indicating that both $D_{1}$ and $D_{2}$ tended to decrease with increasing average pore diameter. The shale samples with a smaller average pore diameter had more micropores and larger fractal dimension, which resulted in a more complicated pore structure and rougher pore surface.

\section{Conclusion}

The following conclusions were drawn from this study:

(1) A large number of randomly distributed organic pores developed in the shale and connected with a small number of inorganic pores, forming many connected pore clusters and microscopic seepage channels for gas storage and migration. Micropores and mesopores in shales provided the main specific surface area and pore volume. The surface dimension $D_{1}$ ranged from 2.773 to 2.923 with a mean value of 2.821 , and the structure dimension $\mathrm{D}_{2}$ varied from 2.853 to 2.899 with a mean value of 2.874 . These variations indicated that there were irregular pore surfaces and sophisticated pore structures in the shale samples.

(2) Both the shale sample size and bedding direction had an impact on pore morphology. The connectivity between pore clusters and the size and number of isolated pore clusters of vertical samples were larger than those of horizontal samples. Moreover, with an increase in the size of the pores, the pore distribution became more uniform, the number of pore clusters increased, and the number of pores in pore clusters increased. Moreover, the connectivity between pore clusters became better, and the number and size of isolated pore clusters decreased peripherally. Notably, the volume of pore clusters had no obvious relationship with the size.

(3) Both the size and bedding direction of the shale samples affected various pore parameters. Compared with the porosity of horizontal shale samples, the porosity of vertical shale samples reduced by about $17 \%$. When the size of the samples was quite small, the porosity had a positive correlation with the size, while the porosity had no relationship with the size when the size reached a certain value. The specific surface area and pore volume of horizontal bedding samples were larger than those of the vertical bedding samples. Besides, the specific surface area and pore volume increased with an increase in the sample size. The size and bedding direction of shale samples correlated with adsorption capacity to a certain extent.

(4) There was a good positive correlation between the fractal dimension $D_{2}$ and porosity and between $D_{2}$ and specific surface area. There was also a moderate positive correlation between $D_{2}$ and pore volume. However, the fractal dimension $D_{1}$ had a weak negative correlation with porosity and specific surface area and moderate negative correlation with pore volume. Besides, both $D_{1}$ and $D_{2}$ tended to decrease with increasing average pore diameter.

\section{Data Availability}

The data used to support the findings of this study are available from the corresponding author upon request.

\section{Conflicts of Interest}

The authors declare that there are no conflicts of interest. 


\section{Authors' Contributions}

All authors have contributed to the creation of this manuscript for important intellectual content and read and approved the final manuscript. Material preparation, data collection, and analysis were performed by Yao Cheng, Yifeng Xie, and Yulin Ma. The first draft of the manuscript was written by Yifeng Xie, and all authors commented on previous versions of the manuscript.

\section{Acknowledgments}

This study was supported by the National Science and Technology Major Project (grant no. 2017ZX05037-001), National Natural Science Foundation of China (grant nos. 51574138 and 51774131), and Discipline Innovation Team Project of Liaoning Technical University (grant nos. LNTU20TD-11). The authors are grateful to the International Science Editing (http://www. internationalscienceediting.com) for editing this manuscript.

\section{References}

[1] D. Dong, Y. Wang, X. Li et al., "Breakthrough and prospect of shale gas exploration and development in China," Natural Gas Industry B, vol. 3, no. 1, pp. 12-26, 2016.

[2] Z. Wang and A. Krupnick, "A retrospective review of shale gas development in the United States: what led to the boom?" Economics of Energy \& Environmental Policy, vol. 4, no. 1, pp. 5-18, 2015.

[3] X. Zhang and Y. Yang, "An overview of shale gas production," Acta Petrolei Sinica, vol. 34, no. 4, pp. 792-801, 2013.

[4] X. Zhang, T. Zhang, and Y. Li, "Research advance in exploration and development of shale gas," Lithologic Reservoirs, vol. 25, no. 2, pp. 116-122, 2013.

[5] Q. Guan, D. Dong, S. Wang et al., "Preliminary study on shale gas microreservoir characteristics of the lower silurian Longmaxi formation in the southern Sichuan Basin, China," Journal of Natural Gas Science and Engineering, vol. 31, pp. 382-395, 2016.

[6] Z. Caineng, D. Dazhong, and W. Yuman, "Shale gas in China: characteristics, challenges and prospects (II)," Petroleum Exploration and Development, vol. 43, no. 2, pp. 182-196, 2016.

[7] R. G. Loucks, R. M. Reed, S. C. Ruppel, and U. Hammes, "Spectrum of pore types and networks in mudrocks and a descriptive classification for matrix-related mudrock pores," AAPG Bulletin, vol. 96, no. 6, pp. 1071-1098, 2012.

[8] Y. Ma, N. Zhong, D. Li, Z. Pan, L. Cheng, and K. Liu, "Organic matter/clay mineral intergranular pores in the Lower Cambrian Lujiaping Shale in the north-eastern part of the upper Yangtze area, China: a possible microscopic mechanism for gas preservation," International Journal of Coal Geology, vol. 137, pp. 38-54, 2015.

[9] U. Kuila, D. K. McCarty, A. Derkowski, T. B. Fischer, T. Topór, and M. Prasad, "Nano-scale texture and porosity of organic matter and clay minerals in organic-rich mudrocks," Fuel, vol. 135, pp. 359-373, 2014.

[10] P. Tiwari, M. Deo, C. L. Lin, and J. D. Miller, "Characterization of oil shale pore structure before and after pyrolysis by using X-ray micro CT,” Fuel, vol. 107, pp. 547-554, 2013.
[11] M. M. Labani, R. Rezaee, A. Saeedi, and A. A. Hinai, "Evaluation of pore size spectrum of gas shale reservoirs using low pressure nitrogen adsorption, gas expansion and mercury porosimetry: a case study from the Perth and Canning Basins, Western Australia," Journal of Petroleum Science and Engineering, vol. 112, pp. 7-16, 2013.

[12] F. Yang, Z. F. Ning, and S. D. Zhang, "Characterization of pore structures in shales through nitrogen adsorption experiment," Natural Gas Industry, vol. 33, no. 4, pp. 135-140, 2013.

[13] X. Shao, X. Pang, Q. Li et al., "Pore structure and fractal characteristics of organic-rich shales: a case study of the lower Silurian Longmaxi shales in the Sichuan Basin, SW China," Marine and Petroleum Geology, vol. 80, pp. 192-202, 2017.

[14] Q. Hu, X. Gao, and Z. Gao, "Pore accessibility and connectivity of mineral and kerogen phases for shales," in Proceedings of the SEG Unconventional Resources Technology Conference, Denver, CO, USA, August 2014.

[15] C. R. Clarkson, N. Solano, R. M. Bustin et al., "Pore structure characterization of North American shale gas reservoirs using USANS/SANS, gas adsorption, and mercury intrusion," Fuel, vol. 103, pp. 606-616, 2013.

[16] D. Lv, D. Wang, Z. Li, H. Liu, and Y. Li, "Depositional environment, sequence stratigraphy and sedimentary mineralization mechanism in the coal bed- and oil shale-bearing succession: a case from the Paleogene Huangxian Basin of China," Journal of Petroleum Science and Engineering, vol. 148, pp. 32-51, 2017.

[17] S. Kelly, H. El-Sobky, C. Torres-Verdín, and M. T. Balhoff, "Assessing the utility of FIB-SEM images for shale digital rock physics," Advances in Water Resources, vol. 95, pp. 302-316, 2016.

[18] K. Jiao, S. Yao, C. Liu et al., "The characterization and quantitative analysis of nanopores in unconventional gas reservoirs utilizing FESEM-FIB and image processing: an example from the lower Silurian Longmaxi Shale, upper Yangtze region, China," International Journal of Coal Geology, vol. 129, pp. 1-11, 2014.

[19] C. Jingwei, Z. Caineng, and Z. Rukai, "New advances in shale porosity research," Advances in Earth Science, vol. 27, no. 12, pp. 1319-1325, 2012.

[20] M. E. Curtis, C. H. Sondergeld, R. J. Ambrose, and C. S. Rai, "Microstructural investigation of gas shales in two and three dimensions using nanometer-scale resolution imaging," AAPG Bulletin, vol. 96, no. 4, pp. 665-677, 2012.

[21] B. Yuan, L. Xiong, L. Zhai, Y. Zhou, G. Chen, and W. ZhangGong, "Transparent synthetic soil and its application in modeling of soil-structure interaction using optical system," Frontiers in Earth Science, vol. 7, p. 276, 2019.

[22] B. X. Yuan, M. Sun, Y. X. Wang, L. H. Zhai, Q. Z. Luo, and X. Q. Zhang, "Full 3D displacement measuring system for 3D displacement field of soil around a laterally loaded pile in transparent soil," ASCE International Journal of Geomechanics, vol. 19, no. 5, Article ID 4019028, 2019.

[23] H. Tian, L. Pan, X. Xiao, R. W. T. Wilkins, Z. Meng, and B. Huang, "A preliminary study on the pore characterization of Lower Silurian black shales in the Chuandong thrust fold belt, southwestern China using low pressure N2 adsorption and FE-SEM methods," Marine and Petroleum Geology, vol. 48, pp. 8-19, 2013.

[24] J. Xiong, X. Liu, and L. Liang, "Experimental study on the pore structure characteristics of the Upper Ordovician Wufeng Formation shale in the southwest portion of the Sichuan 
Basin, China," Journal of Natural Gas Science and Engineering, vol. 22, pp. 530-539, 2015.

[25] A. A. Hinai, R. Rezaee, L. Esteban, and M. Labani, "Comparisons of pore size distribution: a case from the Western Australian gas shale formations," Journal of Unconventional Oil and Gas Resources, vol. 8, pp. 1-13, 2014.

[26] D. Xiao, Z. Lu, S. Jiang, and S. Lu, "Comparison and integration of experimental methods to characterize the full-range pore features of tight gas sandstone-A case study in Songliao Basin of China," Journal of Natural Gas Science and Engineering, vol. 34, pp. 1412-1421, 2016.

[27] A. Li, W. Ding, J. He, P. Dai, S. Yin, and F. Xie, "Investigation of pore structure and fractal characteristics of organic-rich shale reservoirs: a case study of Lower Cambrian Qiongzhusi formation in Malong block of eastern Yunnan Province, South China," Marine and Petroleum Geology, vol. 70, pp. 46-57, 2016.

[28] J. Xiong, X. Liu, and L. Liang, “An investigation of fractal characteristics of marine shales in the Southern China from nitrogen adsorption data," Journal of Chemistry, vol. 2015, 2015.

[29] N. Peng, S. He, Q. Hu et al., "Organic nanopore structure and fractal characteristics of Wufeng and lower member of Longmaxi shales in southeastern Sichuan, China," Marine and Petroleum Geology, vol. 103, pp. 456-472, 2019.

[30] B. B. Mandelbrot, "Les objets fractals: forme, hasard et dimension," 1975.

[31] F. Yang, Z. Ning, and H. Liu, "Fractal characteristics of shales from a shale gas reservoir in the Sichuan Basin, China," Fuel, vol. 115, pp. 378-384, 2014.

[32] H. Bu, Y. Ju, J. Tan, G. Wang, and X. Li, "Fractal characteristics of pores in non-marine shales from the Huainan coalfield, eastern China," Journal of Natural Gas Science and Engineering, vol. 24, pp. 166-177, 2015.

[33] W. Sun, Y. Zuo, Z. Wu et al., "Fractal analysis of pores and the pore structure of the Lower Cambrian Niutitang shale in northern Guizhou province: investigations using NMR, SEM and image analyses," Marine and Petroleum Geology, vol. 99, pp. 416-428, 2019.

[34] W. Ji, Y. Song, Z. Jiang et al., "Fractal characteristics of nanopores in the lower silurian Longmaxi shales from the upper yangtze platform, south China," Marine and Petroleum Geology, vol. 78, pp. 88-98, 2016.

[35] Y. Chen, H. Lin, X. Ding, and S. Xie, "Scale effect of shear mechanical properties of non-penetrating horizontal rocklike joints," Environmental Earth Sciences, vol. 80, p. 192, 2021.

[36] H. Lin, D. Lei, R. Yong, C. Jiang, and S. Du, “Analytical and numerical analysis for frost heaving stress distribution within rock joints under freezing and thawing cycles," Environmental Earth Sciences, vol. 79, p. 305, 2020.

[37] H. Lin, X. Zhang, R. Cao, and Z. Wen, "Improved nonlinear Burgers shear creep model based on the time-dependent shear strength for rock," Environmental Earth Sciences, vol. 79, p. $149,2020$.

[38] Y. Zhao, Y. Wang, W. Wang, L. Tang, Q. Liu, and G. Cheng, "Modeling of rheological fracture behavior of rock cracks subjected to hydraulic pressure and far field stresses," Theoretical and Applied Fracture Mechanics, vol. 101, pp. 59-66, 2019.

[39] Y. L. Zhao, L. Y. Zhang, J. Liao, W. J. Wang, Q. Liu, and L. Tang, "Experimental study of fracture toughness and subcritical crack growth of three rocks under different environments," International Journal of Geomechanics, vol. 20, no. 8, Article ID 4020128, 2020.
[40] Y. L. Zhao, L. Y. Zhang, W. J. Wang, Q. Liu, L. M. Tang, and G. Cheng, "Experimental study on shear behavior and a revised shear strength model for infilled rock joints," International Journal of Geomechanics, vol. 9, Article ID 4020141, 2020.

[41] Y. L. Zhao, C. S. Zhang, Y. X. Wang, H. Lin, and L. M. Tang, "Shear-related roughness classification and strength model of natural rock joint based on fuzzy comprehensive evaluation," International Journal of Rock Mechanics and Mining Sciences, vol. 127, Article ID 104550, 2021.

[42] M. M. Mahamud and M. F. Novo, "The use of fractal analysis in the textural characterization of coals," Fuel, vol. 87, no. 2, pp. 222-231, 2008.

[43] E. M. Schlueter, R. W. Zimmerman, and P. A. Witherspoon, "The fractal dimension of pores in sedimentary rocks and its influence on permeability," Engineering Geology, vol. 48, no. 3-4, pp. 199-215, 1997.

[44] X. Liu, X. Lu, and Q. Hou, "A feasible method for fractal study using gas adsorption isotherm and its application in earth sciences," Advances in Earth Science, vol. 20, no. 2, pp. 201-206, 2005.

[45] B. Hazra, D. A. Wood, V. Vishal, A. K. Varma, D. Sakha, and A. K. Singh, "Porosity controls and fractal disposition of organic-rich Permian shales using low-pressure adsorption techniques," Fuel, vol. 220, pp. 837-848, 2018.

[46] H. Qi, J. Ma, and P.-z. Wong, "Adsorption isotherms of fractal surfaces," Colloids and Surfaces A: Physicochemical and Engineering Aspects, vol. 206, no. 1-3, pp. 401-407, 2002.

[47] S. J. Gregg and K. S. W. Sing, Adsorption, Surface Area, and Porosity, Academic Press, New York, NY, USA, 1982.

[48] S. Brunauer, P. H. Emmett, and E. Teller, "Adsorption of gases in multimolecular layers," Journal of the American Chemical Society, vol. 60, no. 2, pp. 309-319, 1938.

[49] E. P. Barrett, L. G. Joyner, and P. P. Halenda, "The determination of pore volume and area distributions in porous substances. I. Computations from nitrogen isotherms," Journal of the American Chemical Society, vol. 73, no. 1, pp. 373-380, 1951.

[50] R. Yang, F. Hao, S. He et al., "Experimental investigations on the geometry and connectivity of pore space in organic-rich Wufeng and Longmaxi shales," Marine and Petroleum Geology, vol. 84, pp. 225-242, 2017.

[51] X. Liu, J. Xiong, and L. Liang, "Investigation of pore structure and fractal characteristics of organic-rich Yanchang formation shale in central China by nitrogen adsorption/desorption analysis," Journal of Natural Gas Science and Engineering, vol. 22, pp. 62-72, 2015.

[52] H. Fu, X. Wang, L. Zhang et al., "Investigation of the factors that control the development of pore structure in lacustrine shale: a case study of block X in the Ordos Basin, China," Journal of Natural Gas Science and Engineering, vol. 26, pp. 1422-1432, 2015. 